\title{
Integration of Remote Sensing Data and GIS Tools for Accurate Mapping of Flooded Area of Kurigram, Bangladesh
}

\author{
Sadhan Kumar Roy, Subaran Chandra Sarker* \\ Department of Geography and Environmental Science, Faculty of Life and Earth Sciences, \\ Begum Rokeya University, Rangpur, Bangladesh \\ Email: roysadhanges@gmail.com, suba.ju23@gmail.com
}

Received 24 January 2016; accepted 17 April 2016; published 20 April 2016

Copyright (C) 2016 by authors and Scientific Research Publishing Inc.

This work is licensed under the Creative Commons Attribution International License (CC BY). http://creativecommons.org/licenses/by/4.0/

(c) (i) Open Access

\begin{abstract}
Flood is the most devastating disaster in the present world which causes damage to environmental, social, economical and human lives at about $43 \%$ of all natural disasters. There are many flood hazard occurs in Bangladesh during the $19^{\text {th }}$ century and $20^{\text {th }}$ century in the different regions. These flood hazards have more catastrophic damages of huge area within human lives and other necessary properties of Bangladesh. The first step of flood management is to evaluate the area which is under threat of flood disaster. In this study here showed the importance of Remote Sensing (RS) data and Geographic Information System (GIS) tools to manage the flood related problems. Remote Sensing (RS) data and Geographic Information System (GIS) provide a lot of information to flood disaster management. ArcView GIS software tools are used for digitizing the base map and to create a flood risk zone of Kurigram, Bangladesh where images of remote sensing can be helped to determine the flood inundation areas. The integrated application of RS and GIS techniques for monitoring and flood mapping provides information for the decision makers. The study also grows attentions the need of cost-efficient methodology by creating a flood vulnerable map of Bangladesh.
\end{abstract}

\section{Keywords}

Flood, Remote Sensing, GIS, Flood Map

\section{Introduction}

Nowaday, flood is frequent, widespread and the most devastating natural hazardous phenomena in the world. It

"Corresponding author.

How to cite this paper: Roy, S.K. and Sarker, S.C. (2016) Integration of Remote Sensing Data and GIS Tools for Accurate Mapping of Flooded Area of Kurigram, Bangladesh. Journal of Geographic Information System, 8, 184-192.

http://dx.doi.org/10.4236/igis.2016.82017 
is also a common natural hazard in Bangladesh. Flood hazard is very serious in Kurigram district which is surrounded by many small and big rivers. According to UNEP (2002) flood and river bank erosion is the main natural disaster in Kurigram district. These natural disasters are more devastating for Kurigram district because there have no flood forecasting system technology to pre disaster preparedness and post disaster rehabilitation. As well as flood disaster is not a new concept to Kurigram district, it has vast damages on physical, cultural, economic, environmental properties and lives. It so needs to know the nature, causes and mitigation process of flood where flood inundation mapping is the vital elements of flood management. Accurate flood mapping can reduce the flood damages. There is no accurate flood inundation map of Kurigram district which is related to satellite image flood data. Accurate flood inundation map is very important for the proper planning and management the flood hazards. Traditional surveying methods are very time consuming for flood data collection and mapping where the satellite image interpretation and flood inundation mapping is very simple, easy and quick method. RADARSAT and other satellites provide the satellite images data for flood inundation mapping can easily help to reduce the flood damages. For appropriate land use and protect the environment, properties and lives from flood damages in flood prone areas flood mapping are hardly needed. It creates rapidly accessible charts and maps easy to read which facilitate the identification of risk areas and prioritize their mitigation effects [1]. In the past many studies were considered GIS techniques and remote sensing data to produce flood inundation areas map. Many studies were carried out to investigate the hydrological behavior of the floods in Bangladesh [2]-[5]. Remote sensing has provided not only a systematic framework for scientific knowledge of planetary dynamics at various scale but also an effective basis for better informed decision making, regarding issues ranging from planning to forecast and response to natural hazards [6]. Low resolution is especially suitable for large areas mapping for their high revisited time [7]-[9] and new high resolution sensors which are useful for local scale analysis [10] [11]. This study provides an easy, simple and short technique for producing flood inundation maps from various satellite data by using Geographic Information System (GIS) software tools.

\section{Study Area}

Kurigram district is located in Rangpur division situated in northern part of Bangladesh shown in (Figure 1). Total area of Kurigram district is 2296.10 sq.kms where total land covers is 276.45 sq.kms. It is surrounded by Coach Bihar district and West Bengal of India on north portion, and the south portion surrounded by Gaibandha district of Bangladesh, the eastern part is surrounded by Assam province of India, West Bengal, Rangpur and Lalmonirhat districts on the western position. Kurigram district is situated $25^{\circ} 23^{\prime} \mathrm{N}$ to $26^{\circ} 14^{\prime} \mathrm{N}$ latitude and $89^{\circ} 28^{\prime} \mathrm{E}$ to $89^{\circ} 54^{\prime} \mathrm{E}$ longitude shown in (Figure 1). Average height of this district is 13 meter from the mean sea level. There are many big and small river flows over this district. The big rivers are Brahmaputra, Dharla and Tista and smalls are Dudhkumar, Phulkumar, Gangadhar, Jinjiram etc. Tempered climate is seen in the district all the year round. Here annual maximum temperature is $32.3^{\circ} \mathrm{C}$ and minimum $11.2^{\circ} \mathrm{C}$. Annual total rainfall is $2931 \mathrm{~mm}$ (National Encyclopedia of Bangladesh, 2007). Here at about 162,334.28 hectares land is cultivable where total fallow land is $19,312.22$ hectares; $30 \%$ land is single crop, $50 \%$ land is double crop and $20 \%$ land is treble crop.

\section{Materials and Methods}

\subsection{Materials}

The essential materials for this study is in below

- RADARSAT false color images of flood condition of Bangladesh in 1998 and 2004 (with a projection of WGS_84).

- Computer software which include ARCVIEW and ArcGIS 9.3.

- For analyzing flood and river bank data ArcGis9.3 software was used in the study.

- SPSS was used for flood frequency analysis.

\subsection{Methods}

This study demonstrated using topographic data, remotely sensed imagery, the integrated approach of remote sensing and GIS techniques in flood mapping. The remote sensing data especially RADARSAT images were collected from Space Research and Remote Sensing Organization (SPARRSO) and Centre for Environmental and Geographic Information Services (CEGIS). A subset of images covering a district of the region was used 


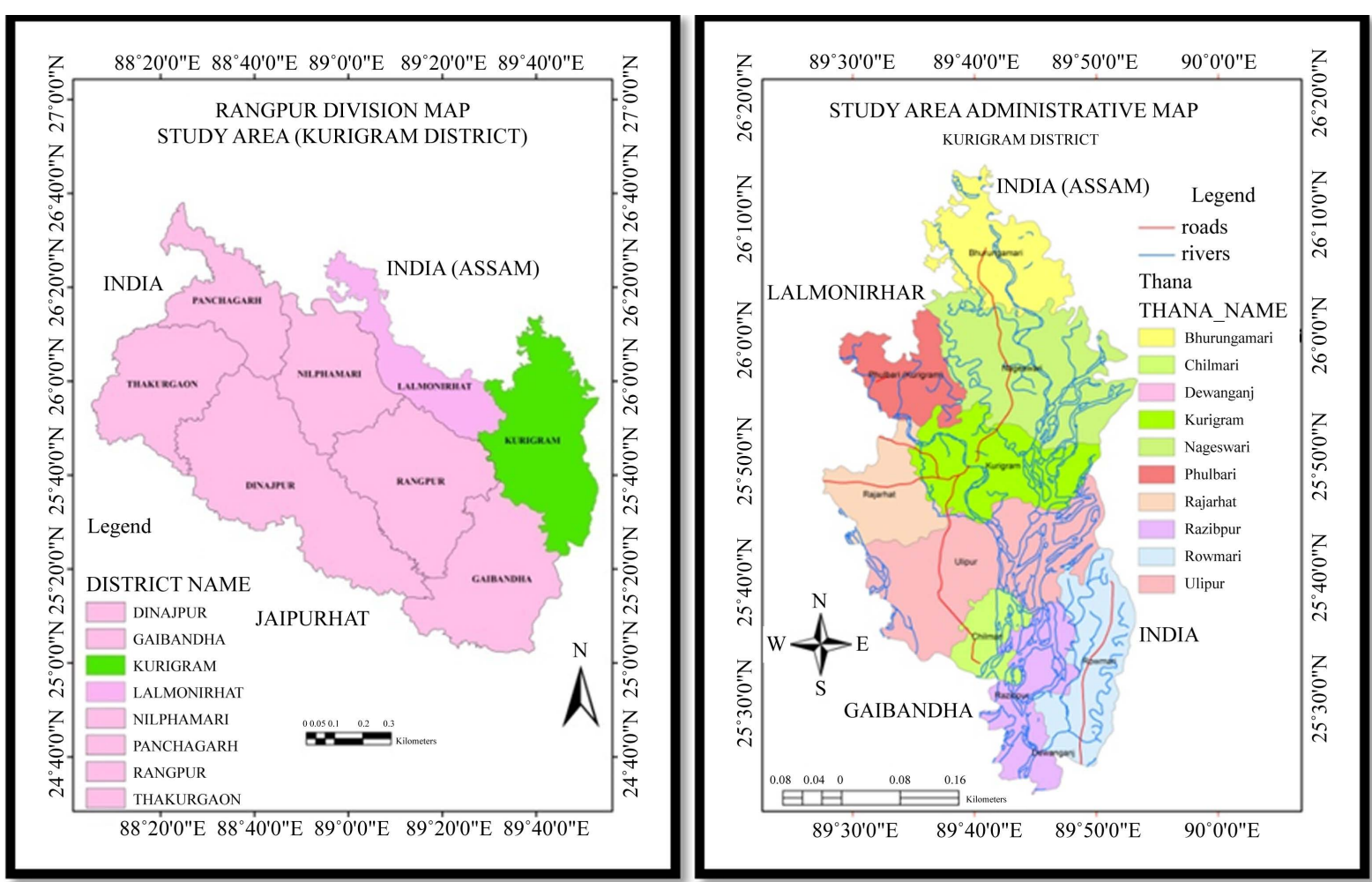

Figure 1. Study area map of Kurigram district (Left) administrative map (Right).

at this stage of the research [12]. Unsystematic errors remain in commercially available remote sensing data; geometric correction was done to reduce the error [13]. All radar amplitude data were firstly geo corrected in the WGS_1984 geographic coordinate system using the open source software package ArcGIS9.3 [14] provided by the Environmental Systems Research Institute (ESRI). The accuracy of classification was assessed based on the evaluation set of the ground truth data [15]. After that the geo referenced images were used with GIS layers. The flooded areas were then derived from the radar amplitude data [16]. Data were carried out using Remote Sensing (RS) and Geographic Information Systems (GIS) [17]. During the GIS manipulation flood data was converted into the attribute data and the overlay process was done to determine the interaction with other features such as drainage and relief for producing the flood inundate maps of flood prone areas. Then it was reclassified into five risk zones of flooded areas are very high, high, moderate, low and very low risk using equal interval of separation based on flooded and non flooded areas [18]. Then, the five risk zones are overlaid on the map to produce the vulnerability map of the flood affected areas. After that the vulnerability map was converted into the digital format to enable the decision makers to assemble necessary data. Without the geospatial data here included some the geospatial data here included some administrative boundaries, road networks and elevation units in GIS layers for produce the map. The range of GIS software error is up to $10 \%$ as a result of digitization and finally overlays analyses performed on conventional maps [18].

\section{Result and Discussion}

\subsection{Mapping Flood of Kurigram District}

Kurigram is a northern district of Bangladesh where total population is 2,069,273. Various seasonal flooding affected the people every year where flood situation is depending on surrounding rivers and total rainfall. The unplanned urban growth of city, unplanned dam and unplanned water bodies filling has made the worse flood situation in Kurigram district. The 1998 and 2004 catastrophic flood is affected the whole district and widely impacted on social, environmental and economical sectors. According to hydrological and meteorological assessment these events are more severe due to the lack of proper flood protection and flood management these lackings lose the huge amount of properties and lives. For creating map of the district for flood management, Re- 
mote sensing data and GIS tools have been used. The 1998 and 2004 flood events show that how the flood maps of Kurigram district were developed. It is true that the using of remote sensing data and GIS tools for flood mapping is quite recent in our Bangladesh. So floods mapping of Kurigram district in 1998 and 2004 is not available and widely. For providing the basic idea of the floods mapping process 1998 and 2004 event is included. Here the 1998 and 2004 events are detailed in this study.

\subsubsection{Mapping Flood of Kurigram District, 1998}

On basis of land cover classification and flood inundation area the study tries to determine the flood vulnerable areas. The study area is shown in (Figure 1). For mapping the flooded area of 1998 and 2004 in Kurigram district two RADARSAT images were used as flood data. The first image is August, 1998 which was collected during the flood and second image is July, 2004 which also collected during rainy season. For avoiding distortions geometric correction was done for establishing the relationship between the coordinate system and image coordinate system. Table 1 here showed that in 1998 about 720 sq.kms areas were non-flooded where the total area was 2296.1 sq.kms. The non flooded area covers the $31 \%$ of total area where the total flooded area is 1575 sq.kms and covered $69 \%$ of total area of the district. In Figure 2, the map gray color has shown the non-flooded area where the pixel counts the 347304 .

According to flood map (Figure 3), the total area of Kurigram district is divided into five vulnerable zones

Table 1. Flood condition of Kurigram district in 1998.

\begin{tabular}{cccc}
\hline Flood Year & Flood Condition & Total Area (sq.kms) & Area in (sq.kms) \\
\hline 1998 & Non Flooded & 2296.1 & 720 \\
1998 & Flooded & 2296.1 & 1575 \\
\hline
\end{tabular}

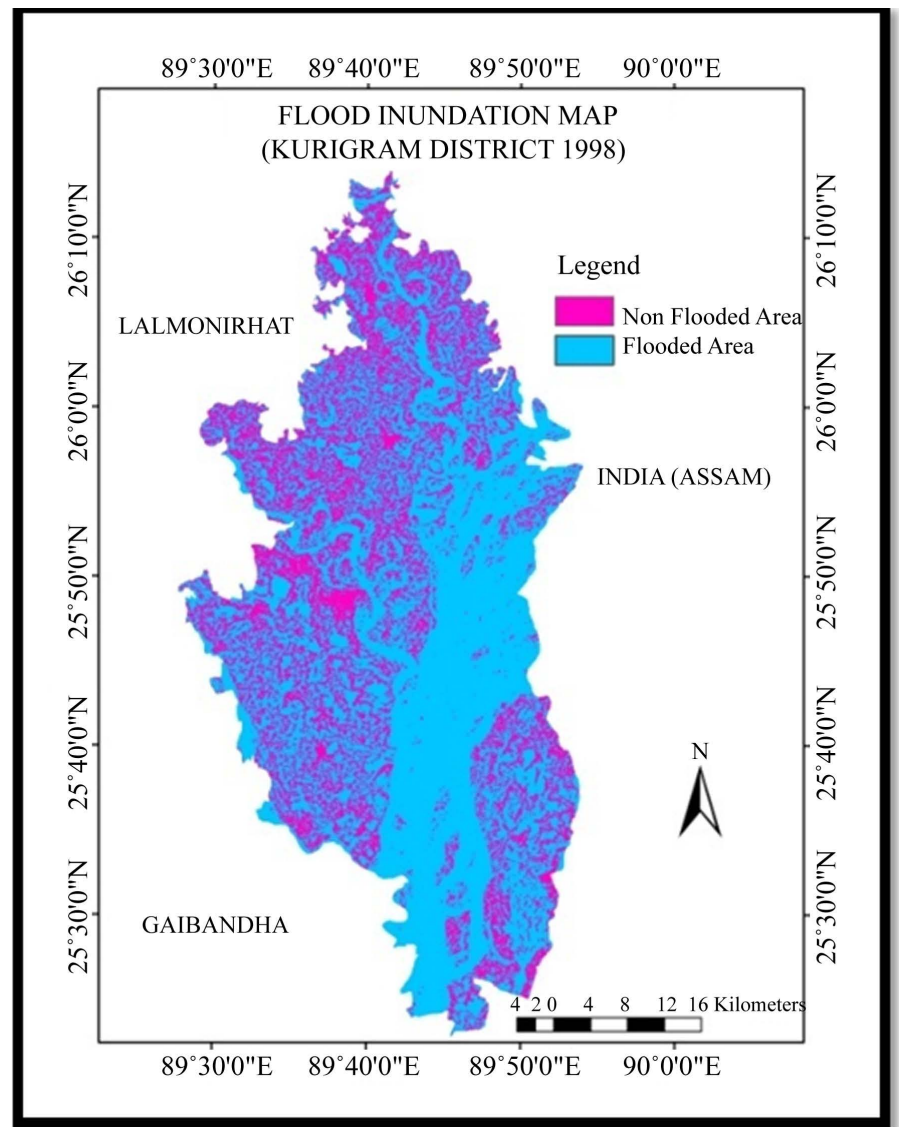

Figure 2. Flood inundation map of Kurigram district 1998. 


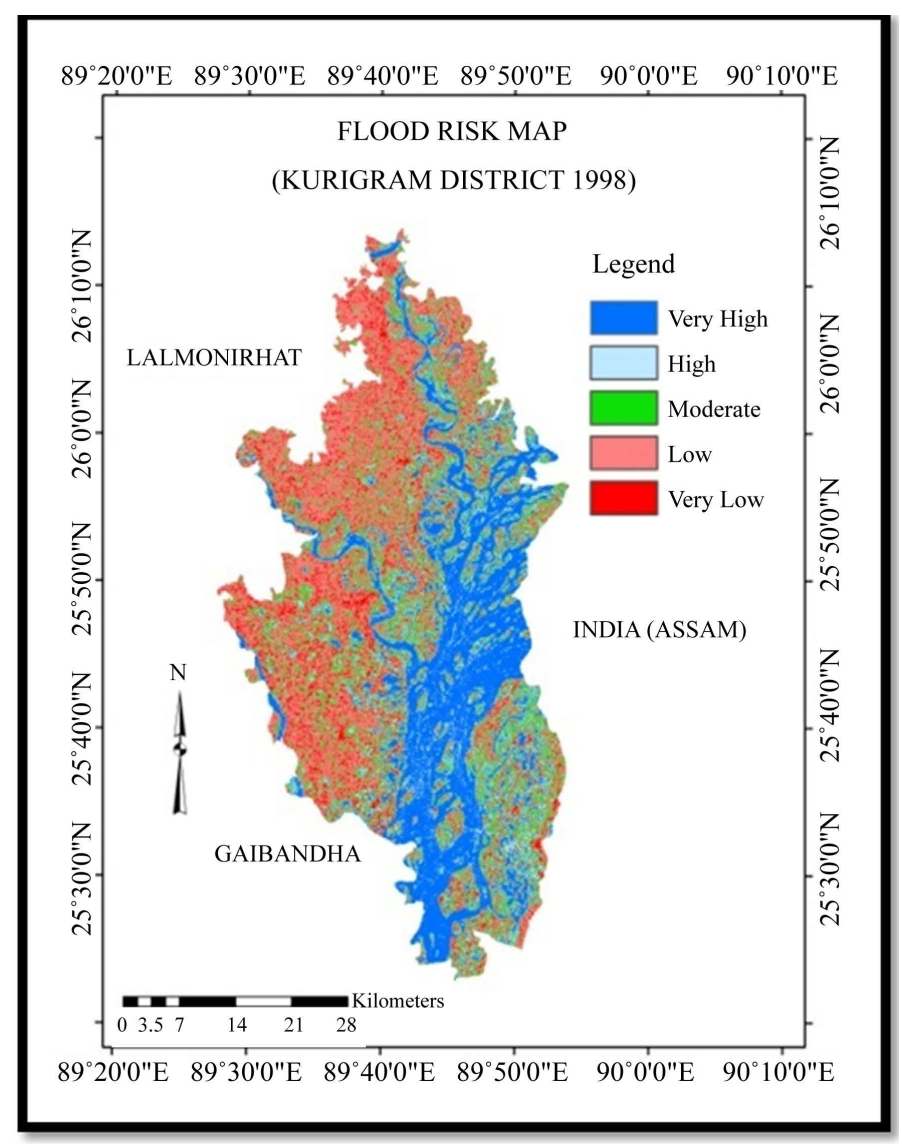

Figure 3. Flood risk map of Kurigram district, 1998.

where the first class is denoted here at very high risk and it's covered 622.75 sq.kms which is $27.12 \%$ of the total area. Second class is high risk zone and it's covered 278.75 sq.kms which is $12.14 \%$ of the total area. Third class is moderate risk zone and it's covered 379.57 sq.kms which is $16.33 \%$ of the total area. Forth class is low risk zone and it's covered 793.94 sq.kms which is $34.58 \%$ of the total area. Fifth class is very low risk zone and it’s covered 222.35 sq.kms which is $9.68 \%$ of the total area shown in (Figure 4).

\subsubsection{Mapping Flood of Kurigram District, 2004}

In 2004 according to Figure 5, about 1040 sq.kms areas were non-flooded where the total area was 2296.1 sq.kms. The non flooded area covers the $46 \%$ of total area. In Figure 5, the map violet color has shown the non-flooded area where the pixel counts the 347304. Otherwise, the 1255 sq.kms area was flooded in 2004. The flooded area covers 54\% area of Kurigram district.

According to flood map, the total area of Kurigram district is divided into five vulnerable zones shown in Table 2 where the first class is denoted here at very high risk and it’s covered 823 sq.kms which is $35 \%$ of the total area. Second class is high risk zone and it's covered 286.56 sq.kms which is $12 \%$ of the total area. Third class is moderate risk zone and it's covered 429 sq.kms which is $18 \%$ of the total area. Forth class is low risk zone and it's covered 600 sq.kms which is $26 \%$ of the total area. Fifth class is very low risk zone and it's covered 156.77 sq.kms which is $9 \%$ of the total area (Figure 6 and Figure 7).

\subsection{Comparisons of Flood Risk of Kurigram between 1998 and 2004}

The 1998 and 2004 flood is more catastrophic which caused worst environmental disaster in Kurigram district and also the memorable history. These floods were prolonged than any known event which consequences in severe damages of economies and untold sufferings to the inhabitants of Kurigram district. The flood hazard areas of these two catastrophic flood of 1998 and 2004 shown in Figure 2 and Figure 5. Here acquired two RADA- 


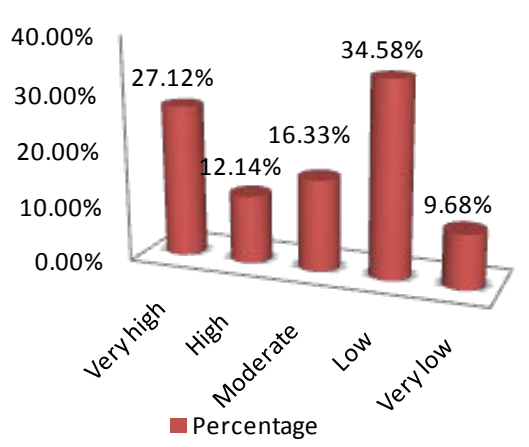

Figure 4. Flood risk percentage of Kurigram district, 1998.

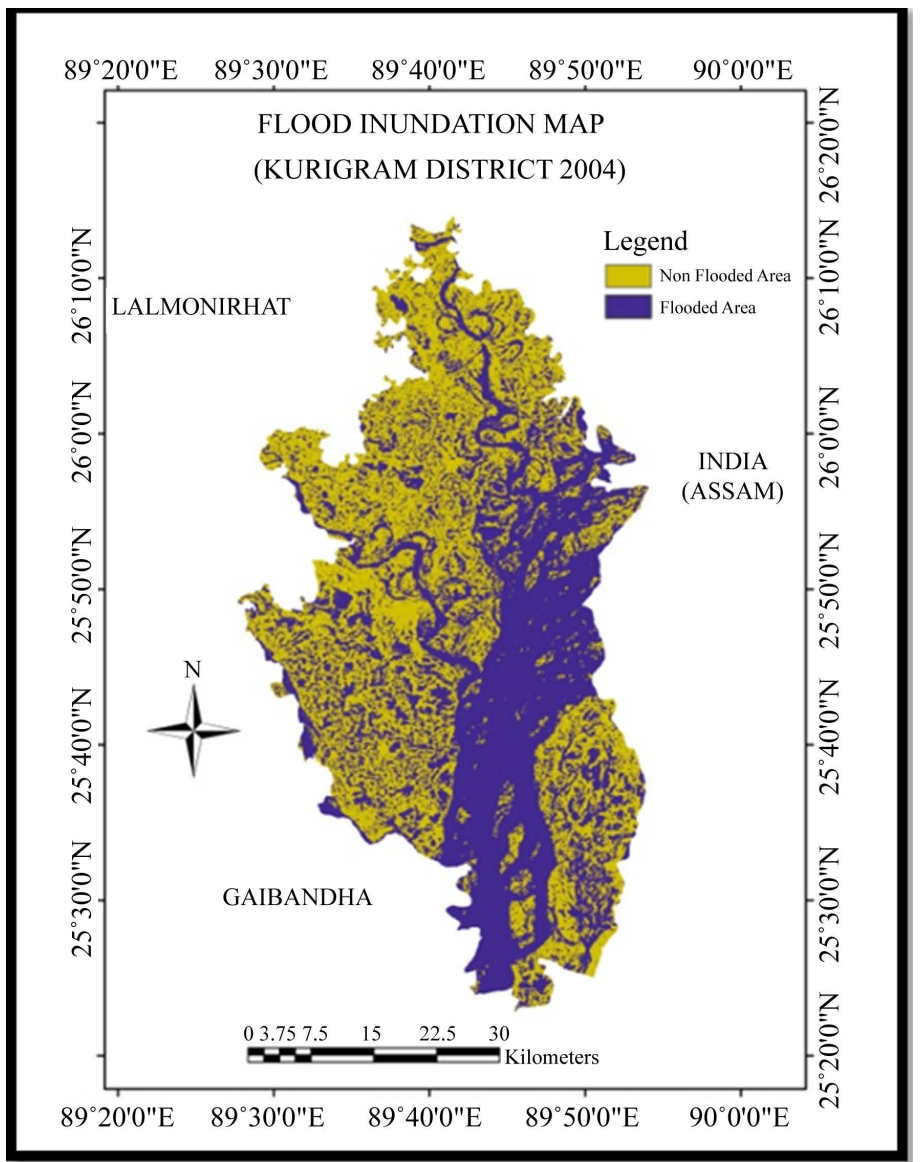

Figure 5. Flood inundation map of Kurigram district, 2004.

Table 2. Flood risk area and percentage of Kurigram district, 2004.

\begin{tabular}{ccc}
\hline Risk Type & Area Covered (sq.kms) & Percentage \\
\hline Very High & 823 & $35 \%$ \\
High & 286.56 & $12 \%$ \\
Moderate & 429 & $18 \%$ \\
Low & 600 & $26 \%$ \\
Very Low & 156.77 & $9 \%$ \\
\hline
\end{tabular}




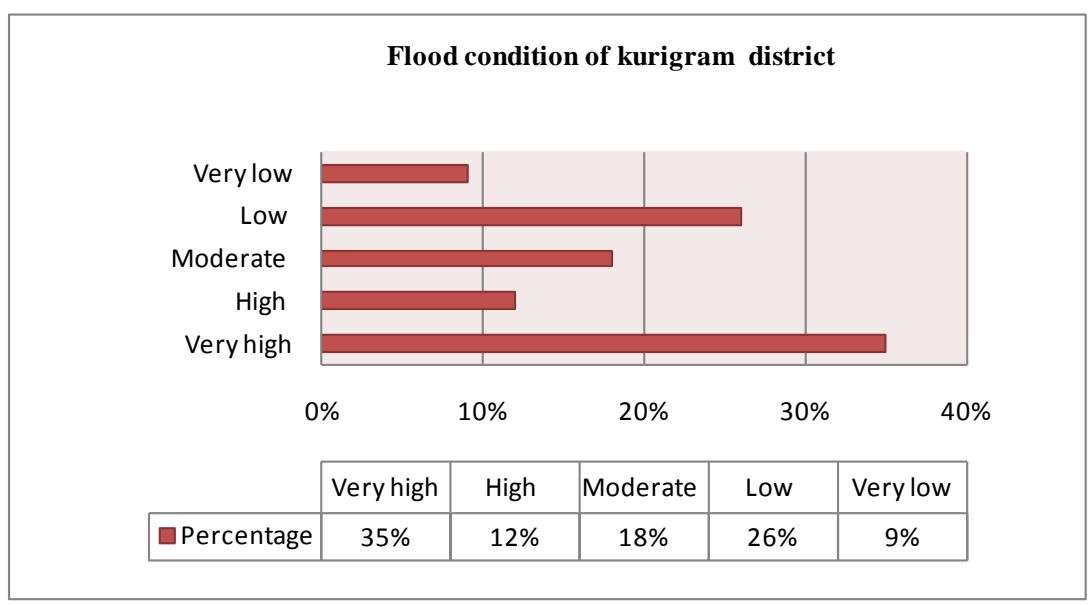

Figure 6. Flood risk percentage of Kurigram district 2004.

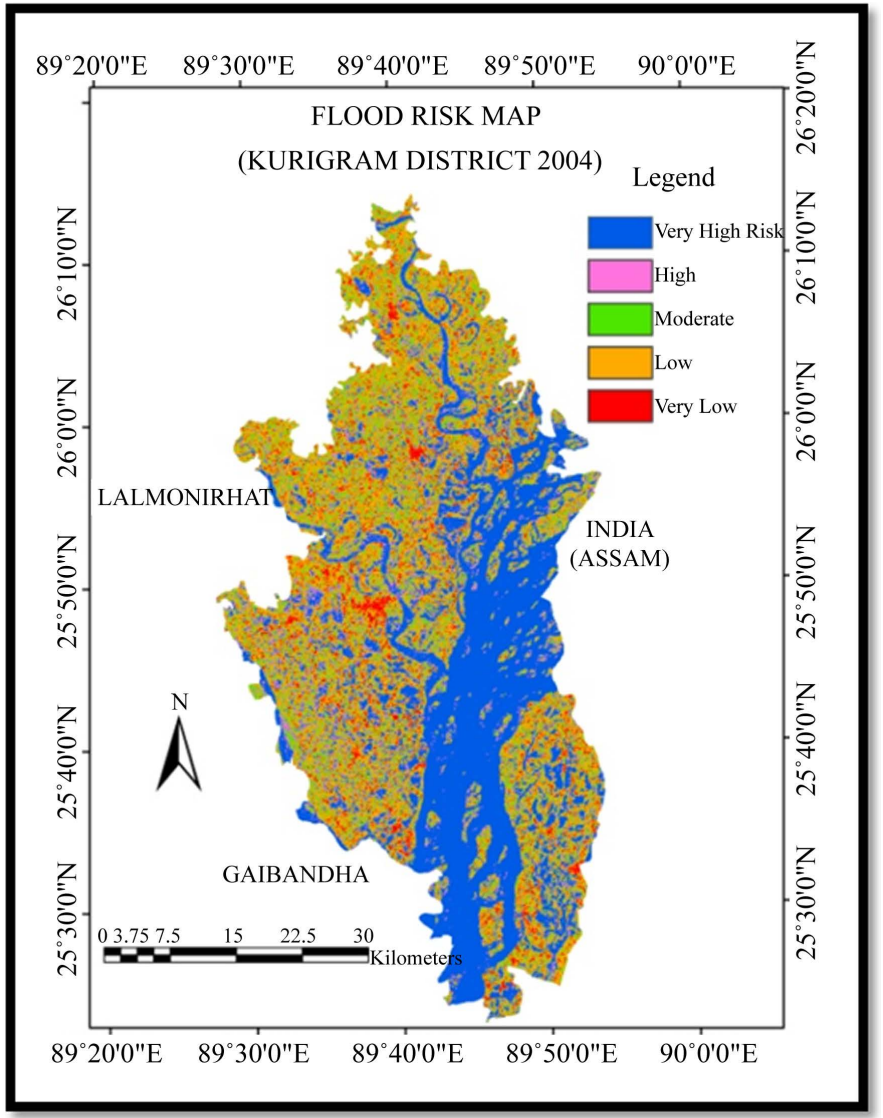

Figure 7. Flood risk map of Kurigram district 2004.

RSAT images covered the whole flood season of 1998 and 2004 monthly July and August.

In the 1998 where the very high risk zone is covered 622.75 sq.kms there in 2004 high risk zone marked 823 sq.kms and 35\% of total area of Kurigram district. There after the high risk zone was covered at about same area and percentage in the both events. As that the moderate risk zone of both areas was 18\% in 2004 and $16.66 \%$ in 1998. Therefore the low and very low risk zone was covered in large area than 1998 to 2004 where the low risk zone percentage in 2004 was 26\% and 1998 was 34.58\%. In the 2004 very low risk zone covered 156.77 sq.kms area and 9\% of total area. Figure 8 shows the area and percentage of flood risk in 1998 and 2004. 
Comperison of flood risk area between 1998 and 2004

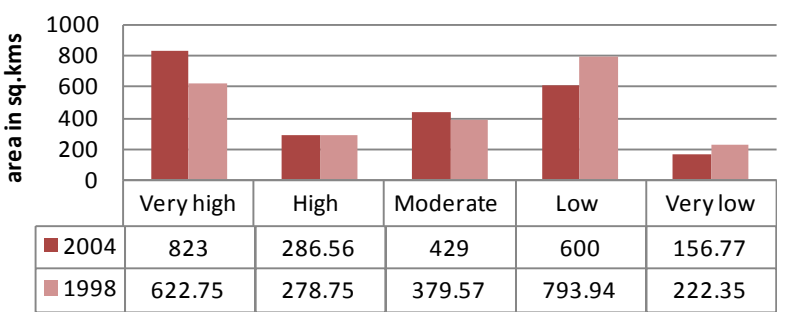

Figure 8. Comparison of flood risk area between 1998 and 2004 of Kurigram district.

The flood map of Kurigram district in 1998 and showed that high concentration of damages of every sides of the river both homestead and agricultural land. These areas are very highly fertile lands which can produce a various types of fruits and crops. Due to lack of detailed flood protection and proper flood management the crops were damaged. There are many roads, motor ways, highway roads and many small roads were damaged. In this study only the inundated area has been mapped. There was no flood plain data were available of the study area. There these flood mapped will be one of the historical event of flood extent can be very effectively used for certain flood modeling and to produce the general flood plain boundaries. These flood modeling and flood boundaries also can help the future urbanization limits and land use pattern to minimize and avoid the properties and human losses.

In Figure 3 and Figure 7, blue color areas showed the very high risk flood zone where the green, light green and grey color areas showed the high, moderate, low and very low flood risk zone. There the green color is more risky than light green color areas. In Figure 3 and Figure 7, red color showed the buildup areas where the different residences were situated. These residential and crop lands fall into flood prone zone of different rivers. Distance is not calculated during analysis of these zones from the rivers because elevation is the main factor than distance for flooding. For example, an area which is situated at the right bank of the river may not be floodaffected for its great height where left bank is far from the river but flood-affected due to its low gentle slope from the river. The vulnerability map of 1998 and 2004 showed (Figure 3 and Figure 7) the probable extent of flood disaster. From the image or the map risk classification, residential buildings, industries and farmlands can be observed within the different risk zones of the river. This analysis suggests that very high risk zones should use very carefully in different purpose by proper flood protection and flood management for decreasing the property and live losses. It also should control the light green zones for land use by the government.

\section{Conclusion}

The using of the remote sensing imagery and GIS tools is very effective for flood mapping in the recent flood events. This study shows how the flood map of a big river system can produce within a very short time by the help of remote sensing data and GIS tools. The maps can help the decision makers to identify the flood risk zones. It also helps the decision makers for planning residential, urban and land use system of a catchment area. It also provides the useful information to the town planners to use relocation, mitigation, modernization, flood protection and flood management system to reduce the properties and live losses. The study also suggests the further use of the remote sensing data and GIS tools for flood risk zones mapping. Here, it is insured that the flood mapping of Kurigram district is quite effective for flood risk management and flood protection. From the flood mapping of Kurigram district of 1998 and 2004, the whole district is divided into five flood frequency categories which are very high risk zones, high risk zones, moderate risk zones, low risk and very low risk zones. The study shows that Kurigram district area comes under high risk due to low gradient and slope watershed and surrounded by numerous small and large rivers and here needs proper flood management by accurate flood mapping.

\section{Acknowledgements}

I would like to thank the Centre for Environmental and Geographic Information Services (CEGIS) and Space Research and Remote Sensing Organization (SPARRSO), Dhaka, Bangladesh for providing me the valuable da- 
ta for my study work. I also thank the Department of Geography and Environmental Science, Begum Rokeya University, Rangpur who has given logistic supports and guidance.

\section{References}

[1] Baplu, G.V. and Sinha, R. (2005) GIS in Flood Hazard Mapping: A Case Study of Kosi River Basin, India. GIS Development Weekly, 1, 1-3.

[2] Chowdhury, J.U., Rahman, R., Islam, B.S.K. and Saiful, A.K.M. (1998) Impact of 1998 Flood on Dhaka City and Performance of Flood Control Works. Dhaka Institute of Food and Drainage Research, Dhaka.

[3] Islam, A.S. and Chowdhury, J.U. (2002) Hydrological Characteristics of the 1998 Flood in Major Rivers, Engineering Concern of Flood. Bangladesh University of Engineering and Technology, Dhaka.

[4] Islam, K.M.N. (2006) Impacts of Flood in Urban Bangladesh: Micro and Macro Level Analysis. A H Development Publishing House, Community Development Library, Dhaka.

[5] Rahman, R., Haque, A., Khan, S.A., Salehin, M. and Bala, S.K. (2005) Salehin Investigation of Hydrologic Aspects of Flood-2004 with Special Emphasis on Dhaka City. Institute of Water and Flood Management (IWFM), Bangladesh University of Engineering and Technology (BUET), Dhaka.

[6] Brivio, P.A., Colombo, R., Maggi, M. and Tomasoni, R. (2002) Integration of Remote Sensing Data and GIS for Accurate Mapping of Flooded Areas. International Journal of Remote Sensing, 23, 429-441. http://dx.doi.org/10.1080/01431160010014729

[7] Berg, A. and Gregiore, J.M. (1983) Use of Remote Sensing Techniques for Rice Production Forecasting in West Africa, (Mali and Guinea: Niger-Bani Project). ESA Satellite Remote Sensing for Developing Countries, Ispra, 161-168.

[8] Barton, I. and Bathols, J. (1989) Monitoring Floods with AVHRR. International Journal Remote Sensing Environment, 30, 89-94. http://dx.doi.org/10.1016/0034-4257(89)90050-3

[9] Anderson, E. (2002) MODIS 250 Image Map Services of Western Tennessee with Inundation Maps. DFO-2001-147, Dartmouth Flood Observatory, Hanover, Digital Media.

[10] Bryant, R.G. and Gilvear, D.J. (1999) Quantifying Geomorphic and Riparian Land Cover Changes Either Sides of a Large Flood Event Using Airborne Remote Sensing: River Tay, Scotland. Geomorphology, 29, 307-321. http://dx.doi.org/10.1016/S0169-555X(99)00023-9

[11] Van Der Sande, C.J., De Jong, S.M. and De Roo, A.P.J. (2003) A Segmentation and Classification Approach of IKONOS-2 Imagery for Land Cover Mapping to Assist Lood Risk and Food Damage Assessment. Journal of Applied Earth Observation and Geoinformation, 4, 217-229.

[12] Kamal, M.M., Passmore, P.J. and Shepherd, I.D.H. (2010) Integration of Geographic Information System and RDARSAT Synthetic Aperture Radar Data Using a Self-Organizing Map Network as Compensation for Realtime Ground Data in Automatic Image Classification. Journal of Applied Remote Sensing, 4, 043534. http://dx.doi.org/10.1117/1.3457166

[13] Dewan, A.M. and Yamaguchi, Y. (2008) Using Remote Sensing and GIS to Detect and Monitor Land Use And Land Cover Change in Dhaka Metropolitan of Bangladesh during 1960-2005. Environmental Monitoring and Assessment, 150, 237-249.

[14] Gstaiger, V., Gebhardt, S., Huth, J., Wehrmann, T. and Kuenzer, C. (2012) Multi-Sensoral and Automated Derivation of Inundated Areas Using TerraSAR-X and ENVISAT ASAR Data. International Journal of Remote Sensing, 33, 7291-7304. http://dx.doi.org/10.1080/01431161.2012.700421

[15] Tso, B. and Mather, P.M. (2001) Classification Methods for Remotely Sensed Data. Taylor \& Francis, London. http://dx.doi.org/10.4324/9780203303566

[16] Huth, J., Gebhardt, S., Wehrmann, T., Schettler, I., Kuenzer, C., Schmidt, M. and Dech, S. (2009) Automated Inundation Monitoring Using TerraSAR-X Multi-Temporal Imagery. Proceedings of the European Geosciences Union General Assembly, Vienna, 19-24 April 2009, 19-24.

[17] Lobo, A. (1997) Image Segmentation and Discriminates Analysis for the Identification of Land Cover Units in Ecology. IEEE Transactions on Geosciences and Remote Sensing, 35, 1136-1145. http://dx.doi.org/10.1109/36.628781

[18] Clement, A.R. (2013) An Application of Geographic Information System in Mapping Flood Risk Zones in a North Central City in Nigeria. African Journal of Environmental Science and Technology, 7, 365-371. 